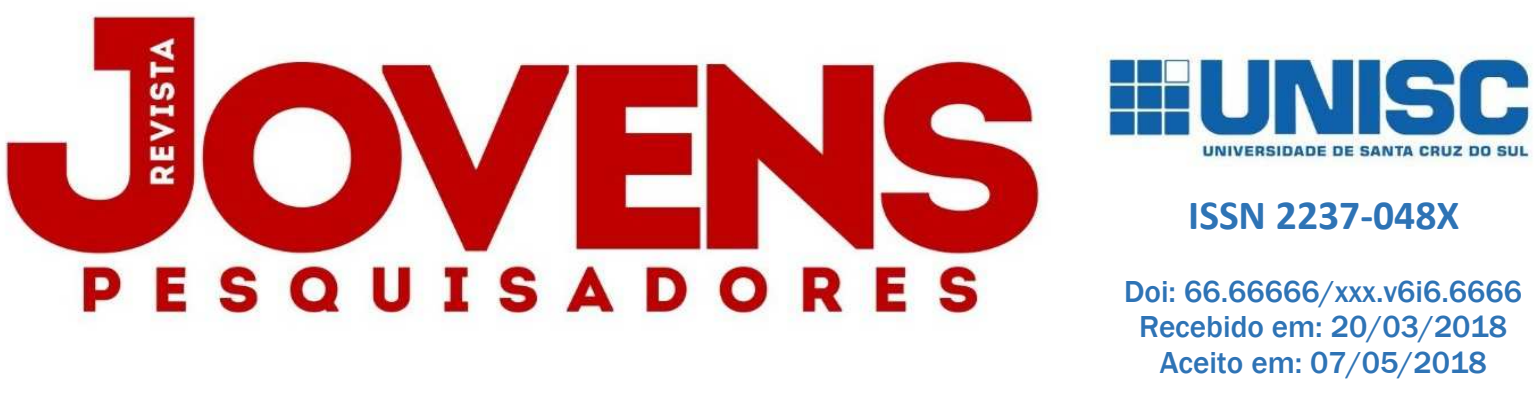

\title{
ACESSO ÀS POLÍTICAS PÚBLICAS EM CIDADES MÉDIAS: A SITUAÇÃO DOS MORADORES DO RESIDENCIAL SANTO ANTÔNIO EM SANTA CRUZ DO SUL/RS
}

\author{
CONCI, N. S. ${ }^{1}$; TIRELLI, C. 2 ; AREOSA, S. V. C. ${ }^{3}$ \\ PALAVRAS CHAVE: Segregação urbana. Políticas públicas. Programa Minha Casa Minha Vida.
}

\section{RESUMO}

0 presente artigo expõe os dados parciais de uma pesquisa iniciada em 2016 e intitulada "Segregação urbana e desigualdades no acesso às políticas públicas em cidades médias". Apresenta dados qualitativos e quantitativos obtidos em um de seus objetos de estudo, o Residencial Santo Antônio, o primeiro conjunto habitacional construído com recursos do Programa Minha Casa Minha Vida (PMCMV), no município de Santa Cruz do Sul/RS, para a população de baixa renda e/ou em situação de vulnerabilidade social, residentes em áreas de risco. Os dados apresentados a seguir foram obtidos através de visitas realizadas ao local para a aplicação de um questionário sociodemográfico; bem como através da realização de entrevistas com os principais gestores desta política pública. Como resultados obtidos, observa-se que as condições de moradia e de acesso aos bens e serviços públicos pouco mudaram após o deslocamento para este local.

\section{ACCESS TO PUBLIC POLICY IN MEDIUM-SIZED CITIES: THE SITUATION OF RESIDENTS OF RESIDENTIAL SANTO ANTÔNIO IN SANTA CRUZ DO SUL/RS}

KEYWORDS: Urban segregation. Public policy. Minha Casa Minha Vida Program.

\begin{abstract}
This article presents the partial data of a research initiated in 2016 and entitled "Urban segregation and inequalities in access to public policies in medium cities". It presents qualitative and quantitative data obtained in one of its objects of study, the Residential Santo Antônio, the first housing complex constructed with resources of the Minha Casa Minha Vida Program (PMCMV), in the municipality of Santa Cruz do Sul/RS, for the population of low income and/or in situations of social vulnerability, living in areas at risk. The data presented below were obtained through visits to the site for the application of a sociodemographic questionnaire; as well as through interviews with the main managers of this public policy. As results obtained, it can be observed that the conditions of housing and access to public goods and services did not change much after the trip to this place.
\end{abstract}

\footnotetext{
${ }^{1}$ Acadêmica do curso de Psicologia na Universidade de Santa Cruz do Sul.

2 Docente do Departamento de Ciências Humanas na Universidade de Santa Cruz do Sul.

3 Docente do Departamento de Psicologia na Universidade de Santa Cruz do Sul.
} 


\section{INTRODUÇÃO}

O Programa Minha Casa Minha Vida (PMCMV) foi implementado a partir de março de 2009, pelo Governo Federal Lula, com o intuito de diminuir o déficit habitacional e impulsionar a economia do país, através de incentivos à produção e compra de novas unidades habitacionais (ROLNIK et al., 2015). Esse Programa contribuiu consideravelmente para o aumento da produção habitacional no Brasil nos últimos anos, "após décadas de ausência de investimentos massivos do governo federal no setor, o que foi bastante comemorado pela comunidade das políticas habitacionais" (MARQUES; RODRIGUES, 2013, p. 159).

Desde a década de 1990 , vêm sendo implementadas no país políticas públicas direcionadas ao combate à pobreza; entre elas o Benefício de Prestação Continuada (BPC), o Programa Fome Zero, o Programa Bolsa Família, o PMCMV, entre outras. Porém, estas políticas públicas não beneficiam a todos de maneira igualitária.

Diante desta questão, no ano de 2016, iniciou-se a pesquisa "Segregação urbana e desigualdades no acesso às políticas públicas em cidades médias". Esta possui o objetivo de analisar como a localização das populações pobres em cidades médias, bem como as condições de sociabilidade que essa localização possibilita, condiciona o acesso às políticas públicas.

O estudo possui como recorte empírico dois conjuntos habitacionais construídos a partir do Programa Minha Casa Minha Vida, no município de Santa Cruz do Sul, uma cidade média do Rio Grande do Sul, com uma população estimada de 127.429 habitantes (IBGE, 2017), e "que tem como principal característica o histórico vínculo econômico, político e sociocultural com a produção do tabaco". (CADONÁ; TIRELLI; AREOSA, 2017, p. 334).

Este artigo vai apresentar dados referentes ao Residencial Santo Antônio, o primeiro conjunto habitacional construído pelo PMCMV no município. 0 mesmo irá mostrar que diferentes níveis de segregação residencial, resultantes dos deslocamentos dessas populações pobres para distintas áreas da cidade afetam as suas condições de vida e o acesso às políticas públicas, desencadeando efeitos muitas vezes não previstos na fase de planejamento da política habitacional.

\section{PROGRAMA MINHA CASA MINHA VIDA}

O Programa Minha Casa Minha Vida (PMCMV) é instituído em 7 de julho de 2009, a partir da promulgação da Lei 11.977, com a finalidade de "criar mecanismos de incentivo à produção e aquisição de novas unidades habitacionais ou requalificação de imóveis urbanos e produção ou reforma de habitações rurais”. (BRASIL, 2009).

A proposta inicial do PMCMV era atender populações de três faixas distintas, com metas, mecanismos de contratação e subvenção financeira diferentes. A primeira faixa destinou-se a famílias com renda mensal entre 0 a 3 salários mínimos. A segunda faixa, a famílias com rendimento mensal entre 3 e 6 salários mínimos. A terceira faixa, por sua vez, destinou-se a famílias com renda mensal entre 6 e 10 salários mínimos. Na primeira fase do Programa, as faixas eram definidas em função do salário mínimo. A partir da segunda fase, que iniciou em 2011, passou-se a estabelecer as faixas sob a forma de valores nominais. Deste modo, a primeira faixa correspondia a famílias com renda mensal de até $\mathrm{R} \$ 1.600,00$; a segunda, famílias com rendimento mensal entre $\mathrm{R} \$ 1.600,00$ e $\mathrm{R} \$ 3.100,00$; e a terceira faixa, por sua vez, destinou-se a famílias com renda mensal entre $\mathrm{R} \$$ 3.100,00 e R\$ 5.000,00. (ROLNIK et al., 2015).

Além de gerar moradias dignas para população de baixa renda, o PMCMV atende também a população rural, e de classe média, em uma parceria entre Estados, Municípios e Entidades junto com o Ministério das Cidades. Têm prioridade de atendimento e acesso à esta política pública:

[...] famílias residentes em áreas de risco, insalubres, que tenham sido desabrigadas ou que perderam a moradia em razão de enchente, alagamento, transbordamento ou em decorrência de qualquer desastre 
natural do gênero; famílias com mulheres responsáveis pela unidade domiciliar; famílias de que façam parte pessoas com deficiência. (BRASIL, 2009).

Outro ponto importante do PMCMV, além do enfrentamento da demanda habitacional, foi que este contribuiu para diminuir os impactos da crise internacional de 2008. Através da movimentação da economia pelo setor da construção civil, houve uma impulsão na geração de empregos pelo fato deste segmento ter uma demanda expressiva de "mão de obra de baixa qualificação, sendo frequentemente mobilizado como elemento de políticas econômicas anticíclicas em momentos de recessão”. (ROLNIK, 2015, p. 130).

A partir disso, alastrou-se pelos mais diversos segmentos do país como um rápido motor de geração de renda e de inclusão social, que caracterizou a década de 2000. (KOPPER, 2015).

\begin{abstract}
Através de seu aparato legal, arquitetônico e político, o PMCMV logrou congregar movimentos sociais, planejadores urbanos, empresários da construção civil e figuras políticas em torno de um modelo de desenvolvimento radicado na concessão da propriedade individual - escriturada e registrada - como forma hegemônica de relacionamento com o território habitado e de superação da pobreza. (KOPPER, 2015, p. 131-132).
\end{abstract}

Atualmente, o PMCMV encontra-se na Fase 3, onde passou por algumas reformulações a partir do ano de 2016 , já no Governo Temer. Conforme mostra uma notícia divulgada pelo site G1 (MATOSO, 2016), nesta nova fase há a criação da Faixa 1,5, que beneficia famílias com renda mensal de até $R$ \$ 2.350,00. Também há alterações nas faixas já existentes, sendo que na Faixa 1, o limite de renda familiar passa de $R \$ 1.600,00$ para $R \$ 1.800,00$; na Faixa 2, o limite passa de $R \$ 3.275$ para $R \$ 3.600,00$; e na Faixa 3, o limite passa de $R \$ 5.000,00$ para $R \$$ $6.500,00$.

\title{
2.1 RESIDENCIAL SANTO ANTÔNIO
}

O Residencial Santo Antônio (Figura 1), localizado no bairro Progresso, foi o primeiro conjunto habitacional construído pelo PMCMV em Santa Cruz do Sul. Suas obras ocorreram através de contrato realizado entre a Caixa Econômica Federal e uma construtora do município.

Figura 1: Vista parcial do Residencial Santo Antônio

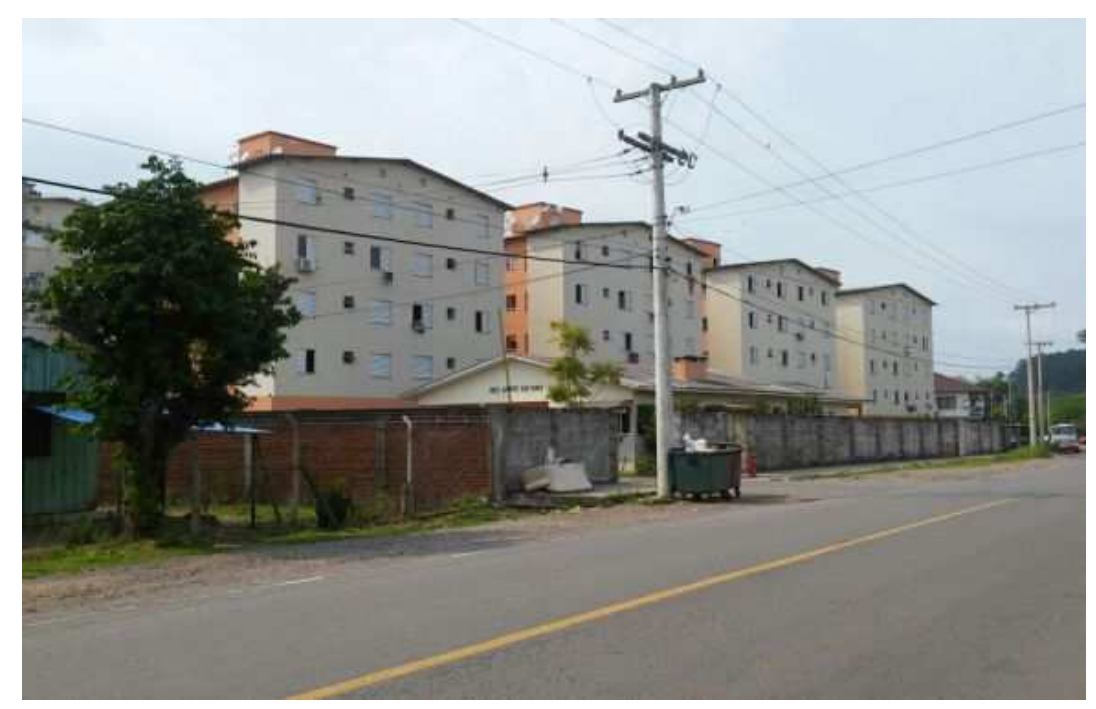

Fonte: Portal Gaz.

A partir dos levantamentos realizados pela área de Serviço Social da Prefeitura Municipal, foram inscritas e préselecionadas 1.112 famílias como futuras beneficiárias. Os critérios para seleção eram famílias de baixa renda moradoras em áreas de risco e insalubres ou em condições de vulnerabilidade social; famílias com mulheres responsáveis pela unidade domiciliar; e famílias de pessoas com deficiência. A partir desses critérios, chegou-se a este número de possíveis beneficiários, porém o condomínio possuía apenas 260 apartamentos, divididos em 
13 blocos. Deste modo, para que todos tivessem a mesma chance de serem contemplados, a Prefeitura Municipal realizou sorteio, onde os mesmos deveriam estar presentes para confirmar sua contemplação. Desta forma, selecionou-se as 260 famílias, alcançando um total estimado de 679 beneficiários. (PREFEITURA MUNICIPAL DE SANTA CRUZ DO SUL, 2013).

Os apartamentos possuem sala, cozinha, dois dormitórios e um banheiro, em uma área total de $43,24 \mathrm{~m}^{2}$. Cada imóvel custou em média $\mathrm{R} \$ \mathbf{4 5 . 0 0 0 , 0 0}$. 0 condomínio possui também área para estacionamento, salão de festas e pracinha, sendo o valor total de investimento $\mathbf{R} \$ 11,7$ milhões. Os mutuários deverão pagar dez por cento do valor de sua da renda bruta total, por um período de dez anos, com parcelas mínimas de $\mathrm{R} \$ 50,00$ mensais. (PREFEITURA MUNICIPAL DE SANTA CRUZ DO SUL, 2013).

Em maio de 2012, as famílias beneficiadas receberam as chaves dos imóveis e puderam, finalmente, se deslocar para o local.

\subsection{SEGREGAÇÃO URBANA}

Conforme Torres (2005), na América Latina, o termo segregação é tomado como sinônimo de "desigualdade", "exclusão" e até mesmo "pobreza". Porém, a segregação urbana não é apenas um sinônimo de pobreza e exclusão, mas se refere também ao grau de separação ou isolamento residencial entre diferentes grupos sociais. (TORRES, MARQUES, BICHIR, 2006).

Para Villaça (2001) o que determina em uma região a segregação de uma classe é a concentração significativa dessa classe mais do que em qualquer outra região. Torres (2005, p. 82) também diz que a segregação pode ser considerada pelo "grau de aglomeração de determinado grupo social/étnico em dada área".

De modo geral, "o conceito de segregação se remete a duas dimensões principais: os padrões de concentração espacial de determinados grupos sociais e o grau de homogeneidade social de determinadas áreas". (TORRES, 2005, p. 83).

Desta maneira, a localização das populações pode não se dar de modo "natural" no espaço, sendo "condicionada pelas dinâmicas de desenvolvimento econômico dos locais e das regiões, pelas políticas que envolvem o ordenamento dos espaços e pelas estratégias individuais e familiares". (CADONÁ; TIRELLI; AREOSA, 2017, p. 328).

\section{METODOLOGIA}

As análises descritas neste estudo foram baseadas em observações diretas e nos dados coletados através de um questionário sociodemográfico aplicado à uma amostra de moradores do Residencial Santo Antônio. Utilizou-se das metodologias quantitativa (uso do questionário) e qualitativa (entrevistas e observação no local).

O questionário aplicado apresentava cinquenta e quatro questões relacionadas ao perfil sócio demográfico e econômico das famílias, bem como questões sobre a percepção dos moradores a respeito das suas condições de vida no local de moradia anterior e no atual. Foram realizados cinco encontros para a aplicação dos questionários, no período de maio a agosto de 2017. Para realizar a análise dos dados dos questionários, as respostas obtidas foram organizadas em tabelas no Microsoft Excel, para posterior análise de dados no Statistical Package for the Social Sciences (SPSS).

Também foram realizadas entrevistas com alguns dos principais gestores e atores da política pública habitacional no município. As mesmas foram gravadas em áudio e posteriormente transcritas para sua análise e categorização. 


\title{
4 DISCUSSÃO E RESULTADOS
}

\subsection{A REALIDADE ENCONTRADA DO RESIDENCIAL SANTO ANTÔNIO}

Inicia-se a apresentação dos resultados quantitativos da pesquisa, apresentados em forma de gráficos para melhor visualização e discussão.

Conforme mostra a Figura 2, pode-se verificar que a grande maioria dos imóveis do Residencial pertencem a mulheres chefes de família. Isso pode refletir uma das disposições do PMCMV, que dá prioridade de aquisição de imóvel para mulheres responsáveis pela unidade domiciliar.

Figura 2: Distribuição por gênero

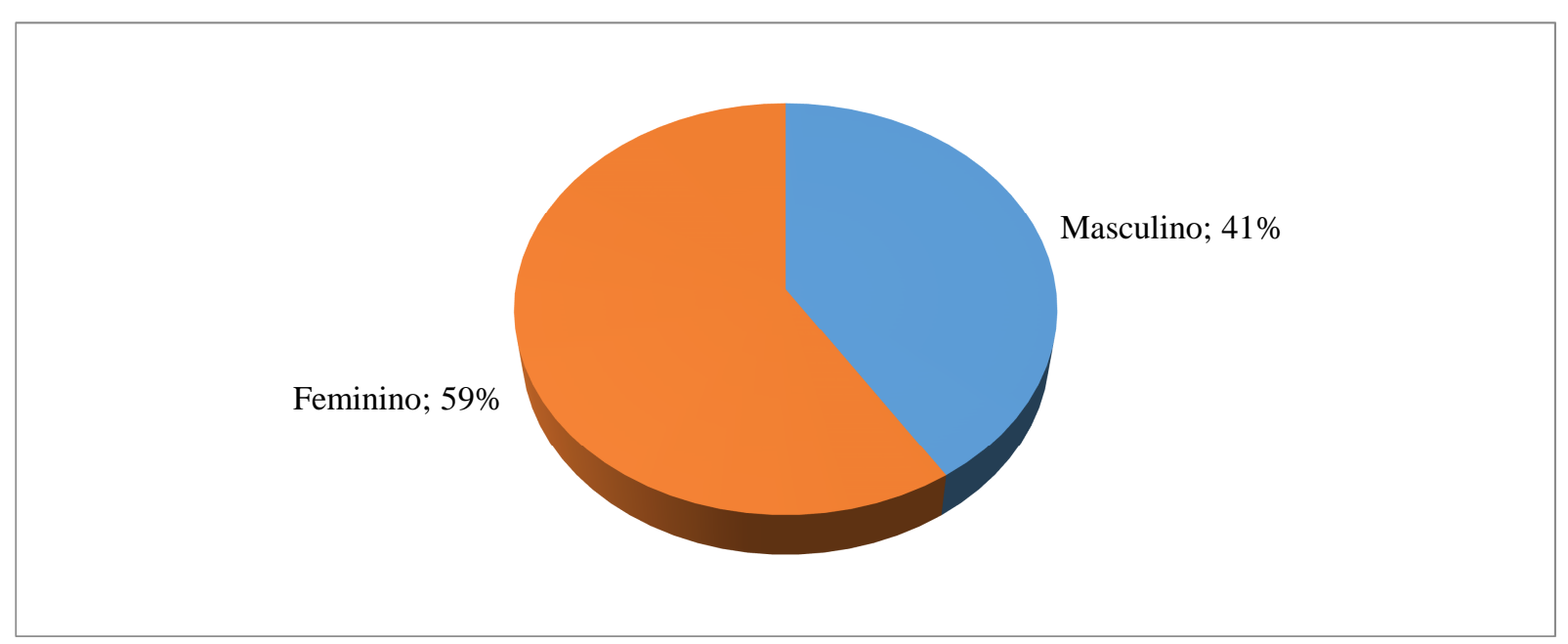

Fonte: produção original com base na análise dos dados.

Segundo Lima (2012), as principais justificativas que levam à concessão da titularidade residencial feminina referem-se à inquestionável importância das mulheres na dinâmica familiar, onde muitas vezes, são responsáveis pelo sustento, pela educação e criação dos filhos, além do trabalho doméstico, sem a presença de um companheiro.

\footnotetext{
Diante deste quadro, as mulheres acabam por se responsabilizar pelo trabalho dentro e fora de casa, bem como pela integração dos membros da família e pela busca de novas oportunidades de trabalho. Em decorrência deste acúmulo de tarefas, as mulheres se tornam as maiores prejudicadas pela falta de serviços públicos tais como saúde, educação (creches) e infraestrutura urbana (escola, luz, água, esgoto, coleta de lixo etc.), verificando-se a necessidade da realização de políticas voltadas para sua autonomia tais como a de Titularidade Residencial Feminina, através da conquista da moradia própria com o documento da casa em seu nome. (LIMA, 2012, p. 77).
}

Segundo Silva (2015, p. 74) "o direito à moradia para as mulheres ainda se relaciona a condição de opressão e desigualdade a que estas estão submetidas pelo sistema patriarcal”.

\begin{abstract}
Quando uma mulher tem seu acesso à moradia e à terra limitados, isso não afeta só a garantia de suas necessidades materiais imediatas, como reitera sua posição de subordinação e dependência sociais em função de seu gênero. Nesse sentido, o direito à moradia da mulher não deve ser considerado enquanto uma reiteração de seu papel de gênero, que a coloca como pertencente ao espaço doméstico. Pelo contrário, deve implicar na garantia de condições materiais que permitam às mulheres estarem em posição de maior autonomia. (SILVA, 2015, p. 74).
\end{abstract}

Sendo assim, a questão da prioridade de mulheres responsáveis pela família para obtenção de imóveis próprios pelas políticas habitacionais deve ser vista como uma questão de maior autonomia das mesmas, diante da desigualdade de gênero existente. 
Outro dado obtido, é o de que a maioria das famílias encontra-se na faixa de renda de até dois salários mínimos, como mostra a Figura 3. 0 que chama a atenção, é que há um número expressivo de pessoas que vivem com menos de um salário mínimo, com apenas o auxílio de benefícios como o Programa Bolsa Família $(43,20 \%$ dos moradores). Mais da metade dos moradores (53\%) recebe algum tipo de benefício.

\begin{abstract}
A composição dos arranjos domiciliares brasileiros vem se modificando ao longo dos anos, como decorrência tanto de fatores demográficos quanto dos socioeconômicos. De um lado, a queda da fecundidade, o aumento da frequência de divórcios e a sobremortalidade masculina - que leva, com o envelhecimento populacional, ao aumento da viuvez feminina - estão entre os fenômenos sociodemográficos que diretamente afetam a composição das famílias, diminuindo o seu tamanho, reduzindo o número de crianças, elevando a idade média e aumentando a proporção de domicílios unipessoais, sobretudo femininos. (WAINMAN, TURRA, AGOSTINHO, 2006, p.427).
\end{abstract}

Figura 3: Distribuição por renda

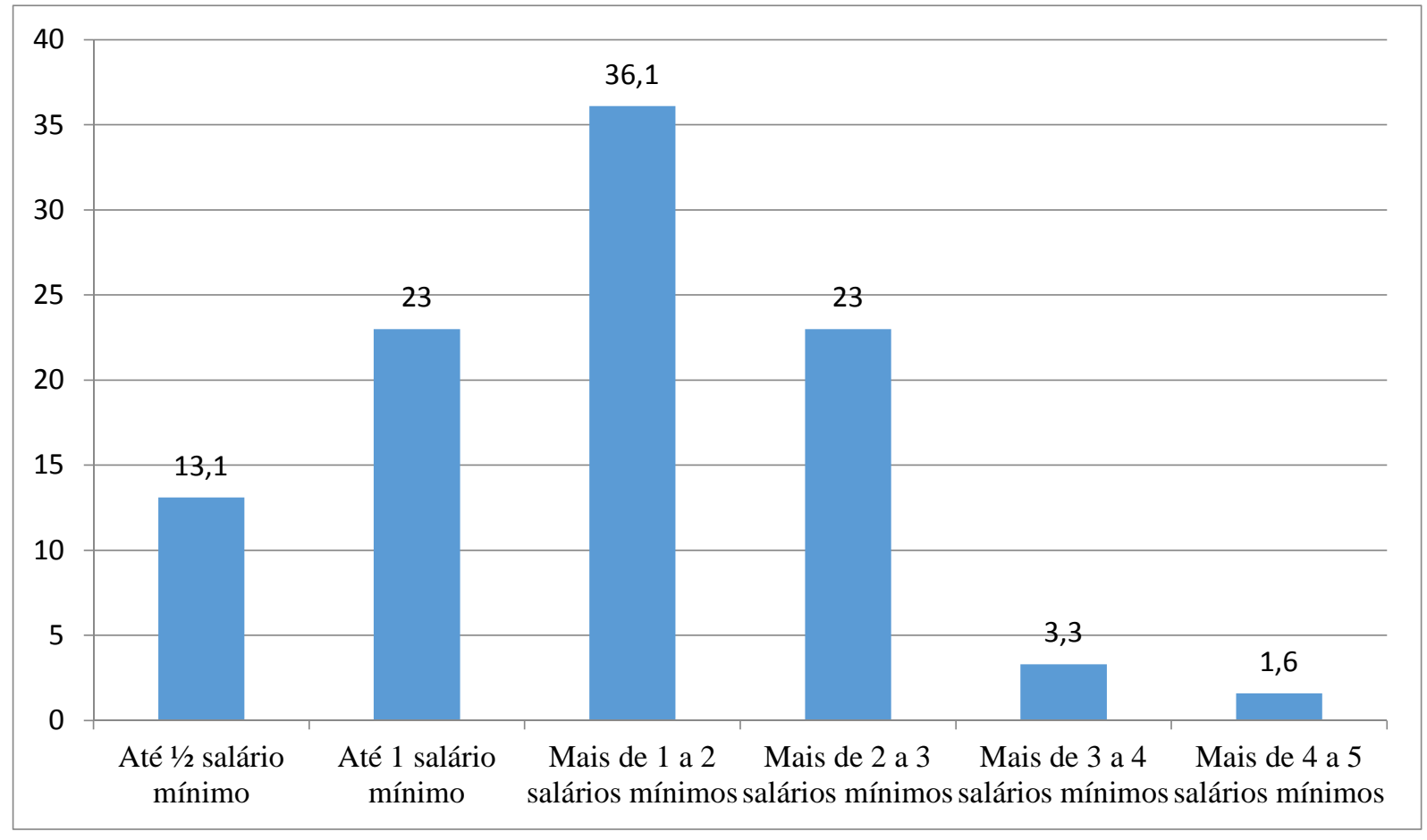

Fonte: produção original com base na análise dos dados.

Há também muitas pessoas desempregadas ou em condições precárias de trabalho, que trabalham de forma autônoma, sem carteira assinada, fazendo os populares "bicos", como evidencia a Figura 4.

Segundo Gomes e Amitrano (2005) as chances de conseguir um emprego podem ser menores em certas áreas da região, seja pela escassez de ofertas de emprego no local ou pelas sérias deficiências sociais. "Isso implica que as pessoas moradoras de áreas mais pobres têm menores chances de estar empregadas não só por residirem em áreas com pequena oferta de emprego, como também porque estão inseridas em comunidades com baixo capital social". (GOMES; AMITRANO, 2005, p. 192).

Deste modo, o alto índice de pessoas desempregadas e/ou em situações precárias de trabalho, como é visto no Residencial Santo Antônio, também podem ser considerados reflexos da crise econômica brasileira, a qual diminuiu consideravelmente a oferta de empregos em vários setores. 
Figura 4: Distribuição por atividades de trabalho

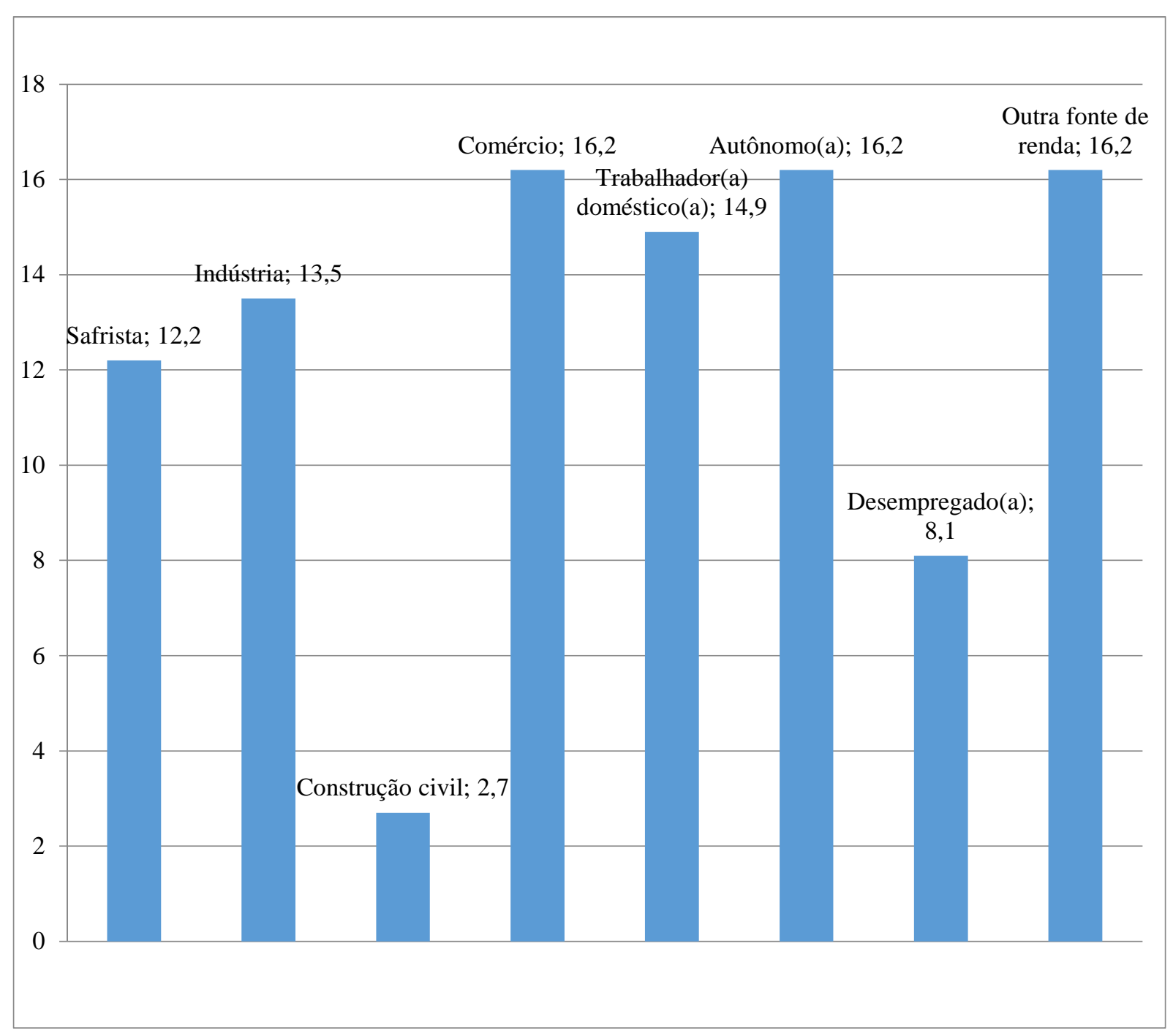

Fonte: produção original com base na análise dos dados.

Segundo Paula e Pires (2017), a economia brasileira, entre 2004 e 2013, passou por um período de expansão, em que houve uma taxa de crescimento média de quatro por cento ao ano. Através disso, houve também uma grande melhoria na distribuição de renda do país, e consequentemente, diminuição dos índices de pobreza. A partir de 2014, a economia passa a sofrer uma forte e prolongada recessão, sendo que em 2015-2016, a taxa de crescimento média do PIB ficou negativa em 3,7\%, acompanhado de uma piora em vários indicadores sociais.

Durante o período de aplicação dos questionários, foi comum escutar dos moradores que dentro do Residencial as pessoas não costumam se ajudar. Embora os entrevistados digam que ali "é cada um por si" percebe-se que existe uma rede de ajuda mútua entre grupos de moradores, onde amparam e compartilham o pouco que têm, seja através de empréstimos, doações de alimentos, cuidados com crianças, doentes, até mesmo com os apartamentos.

A partir das questões referentes às condições de vida antes e depois da mudança para o residencial, conclui-se que não houve modificações significativas no acesso dessa população às políticas públicas em geral (saúde, 
educação, assistência, transporte, saneamento). Esses dados indicam que os moradores já possuíam condições de vida muito semelhantes nos seus locais de origem, com o mesmo tipo de oferta de serviços e bens públicos. Já residiam em bairros periféricos, principalmente na região sul do município, caracterizado pela concentração das indústrias fumageiras. (CADONÁ; TIRELLI; AREOSA, 2017).

A única exceção, diz respeito às condições de moradia que, na visão dos entrevistados, encontra-se bem melhor que na situação anterior. Contribui ainda para esta questão, o fato de ter o próprio imóvel, livrando a família dos valores abusivos dos aluguéis, pagando apenas um valor mínimo mensal referente à prestação do financiamento.

Segundo Ribeiro (2015, p. 13) "a conquista da casa própria pode trazer consigo um grande arcabouço simbólico e sua concretização pode representar, para as pessoas que antes não possuíam uma situação habitacional estável, a conquista da cidadania". Com a aquisição da casa própria, os moradores empoderam-se e tornam-se autônomos; têm seu próprio "[...] espaço de independência não apenas financeira, mas de controle e poder para compor a suas vidas conforme seus desejos. Buscam um sentimento de pertencimento nesse novo lugar". (RIBEIRO, 2015, p. 42).

De acordo com os respondentes, o grande problema existente no local hoje, é a falta de segurança e o consequente aumento da violência dentro do condomínio, ocasionado pelas invasões de apartamentos por parte de distintas facções de traficantes e seus protegidos. Esta questão foi reiterada por grande parte dos entrevistados que afirmam que hoje vivem com medo e muitos desejam outro local para morar. Ressaltam também que há descaso do Poder Público que simplesmente abandonou esta população e diz que os problemas existentes nada tem a ver com a Prefeitura, mas sim com a gestão anterior que estava no município quando da implantação do Programa.

\section{CONSIDERAÇÕES FINAIS}

Este estudo demonstra a importância da política habitacional num país desigual como o Brasil e reforça a necessidade de planejamento e acompanhamento em todas as fases de implantação das políticas públicas. Programas como o Minha Casa Minha Vida são importantes estratégias para o enfrentamento de problemas sociais, além de auxiliarem na diminuição dos índices de pobreza.

Através da análise dos dados obtidos pela aplicação de questionário com os moradores do Residencial Santo Antônio, entende-se que as condições de acesso aos bens e serviços públicos pouco mudou após a mudança para este local. De modo geral, os moradores consideram que suas condições melhoraram, pois agora possuem casa própria, porém ainda se faz necessário investimentos no âmbito social desta população que continua segregada.

\section{REFERÊNCIAS}

BRASIL. Lei n. 11.977, de 7 de julho de 2009. Dispõe sobre o Programa Minha Casa Minha Vida e a regularização fundiária de assentamentos localizados em áreas urbanas. Diário Oficial [da] República Federativa do Brasil, Brasília, DF, 7 jul. 2009. Disponível em: <http://www.planalto.gov.br/ccivil_03/_ato2007-2010/2009/lei/l11977.htm>. Acesso em: 07 mar. 2018. CADONÁ, M. A.; TIRELLI, C.; AREOSA, S. V. C. Políticas habitacionais, segregação residencial e desigualdade no acesso às políticas públicas: uma análise a partir do acesso a serviços públicos de saúde. Redes. Santa Cruz do Sul. v. 22, n. 1, p. 326345, jan./abr. 2017.

GOMES, S.; AMITRANO, C. Local de moradia na metrópole e vulnerabilidade ao (emprego e) desemprego. In: MARQUES, E.; TORRES, H. (Org.). São Paulo: segregação, pobreza e desigualdades sociais. São Paulo: Editora Senac, 2005. p. 169-194. INSTITUTO BRASILEIRO DE GEOGRAFIA E ESTATÍSTICA. IBGE Cidades: Santa Cruz do Sul. 2017. Disponível em: <https://cidades.ibge.gov.br/brasil/rs/santa-cruz-do-sul/panorama>. Acesso em: 13 mar. 2018.

KOPPER, Moisés. Entre o mercado e o governo: as políticas habitacionais e a financeirização da moradia no Brasil. Civitas. Porto Alegre, v. 17, n. 1, p. 131-137, jan./abr. 2017. Disponível em:

<http://revistaseletronicas.pucrs.br/ojs/index.php/civitas/article/view/25166/15552>. Acesso em 22 dez.2017. LIMA, Denise Furtado Alencar. A política de titularidade residencial feminina no contexto da política pública habitacional. 2012. 129 f. Dissertação (Mestrado Acadêmico em Políticas Públicas e Sociedade) - Universidade Estadual do Ceará, Fortaleza, 2012. Disponível em: < http://www.uece.br/politicasuece/dmdocuments/denise_furtado.pdf>. Acesso em: 15 mar. 2018. 
MARQUES, E.; RODRIGUES, L. O Programa Minha Casa Minha Vida na metrópole paulistana: atendimento habitacional e padrões de segregação. Rev. Brasileira de Estudos Urbanos e Regionais. São Paulo. v.15, n. 2, p. 159-177, nov. 2013. Disponível em: <http://rbeur.anpur.org.br/rbeur/article/view/4740>. Acesso em: 11 dez. 2017.

MATOSO, Filipi. Governo lança terceira fase do Programa Minha Casa Minha Vida. G1. Brasília. 30 mar. 2016. Política. Disponível em: <http://g1.globo.com/politica/noticia/2016/03/governo-lanca-terceira-fase-do-programa-minha-casa-minhavida.html>. Acesso em: 08 mar. 2018.

PAULA, L. F.; PIRES, M. Crise e perspectivas para a economia brasileira. Estudos Avançados. São Paulo. v. 31, n. 89, p. 125144, jan./abr. 2017. Disponível em: <http://www.scielo.br/scielo.php?script=sci_arttext\&pid=S010340142017000100125>. Acesso em: 16 mar. 2018.

PREFEITURA Municipal de Santa Cruz do Sul. Plano de intervenção de trabalho técnico social. Santa Cruz do Sul: Prefeitura Municipal de Santa Cruz do Sul, 2013.

RIBEIRO, Graziela Fernanda. O significado da casa própria para os moradores do Residencial Viver Bem no município de Santa Cruz do Sul-RS. 2015. 60 f. Trabalho de conclusão de curso (Curso de Psicologia) - Universidade de Santa Cruz do Sul, Santa Cruz do Sul, 2015. Disponível em: <https://repositorio.unisc.br/jspui/handle/11624/977>. Acesso em: 13 mar. 2018. ROLNIK, R. et al. O Programa Minha Casa Minha Vida nas regiões metropolitanas de São Paulo e Campinas: aspectos socioespaciais e segregação. Cadernos Metrópole, São Paulo, v. 17, n. 33, p. 09-13, mai. 2015. Disponível em: <http://www.scielo.br/pdf/cm/v17n33/2236-9996-cm-17-33-0009.pdf>. Acesso em: 17 out. 2017.

SILVA, Kamila Anne Carvalho da. Mulheres e o direito à moradia: uma análise a partir do Programa Minha Casa Minha Vida. 2015. 84 f. Trabalho de conclusão de curso (Faculdade de Direito, Setor de Ciências Jurídicas) - Universidade Federal do Paraná, Curitiba, 2015. Disponível em:

<https://acervodigital.ufpr.br/bitstream/handle/1884/42165/17.pdf?sequence=1\&isAllowed=y>. Acesso em: 15 mar. 2018.

TORRES, H. da G.; MARQUES, E. C.; BICHIR, R. M. Políticas públicas, pobreza urbana e segregação residencial. In: CUNHA, José Marcos Pinto. Novas metrópoles paulistas: população, vulnerabilidade e segregação. Campinas: Nepo/Unicamp, 2006. p. 231-254,

TORRES, Haroldo. Medindo a segregação. In: MARQUES, E.; TORRES, H. (Org.). São Paulo: segregação, pobreza e desigualdades sociais. São Paulo: Editora Senac, 2005. p. 81-100.

VILLAÇA, Flávio. A segregação urbana. In: Espaço intra-urbano no Brasil. São Paulo: Studio Nobel, 2001, p. 141-155. WAINMAN, S.; TURRA, C. M.; AGOSTINHO, C. S. Estrutura Domiciliar e Distribuição da Renda Familiar no Brasil. In: BARROS, R. P.; FOGUEL, M. N.; ULYSSEA, G. (Org.). Desigualdade de renda no Brasil: uma análise da queda. Brasília: Ipea, 2006. p.423446. 